\title{
ロボットマニピュレータの学習的最適軌道計画 一最適軌道探索回数の一減少法一
}

$$
\text { 逢 坂一正 }{ }^{* *} \text { ・小野 敏 郎 }{ }^{* * *}
$$

\section{A Learning Optimal Trajectory Planning of Robotic Manipulators* \\ -A Decreasing Method of Computing Iteration Number in Optimal \\ Trajectory Search-}

Kazumasa OHSAKA ${ }^{* *}$ and Toshiro ONO ${ }^{* * *}$

\begin{abstract}
A number of trajectory planning algorithms exist for calculating the joint positions, velocities, and torques which will drive a robotic manipulator along a given geometric path. This paper presents a learning method for optimal trajectory planning of robotic manipulators of which all joints are rotational. When the start and end points of end effector are given in the Cartesian coordinates, the Fourier coefficients representing each joint velocity and interval of motion which specify the optimal trajectory in joint coordinates are searched by using the method of steepest descent. In the searching process, a learning algorithm based on the idea of linear approximation and utilization of the information on the known optimal trajectories is introduced. As numerical examples, the trajectories of two-link manipulator are simulated and the learning effect is confirmed.
\end{abstract}

\section{1. まえがき}

ロボットの知能化に関する研究は重要で, 近年, 種々 の問題が考察されているが、ママニヒュレータの学習制御 あその一つの分野である. ロボットマニピュレータの制 御に扔いて, 軌道制御之軌道計画は非常に重要な問題で ある. このうち軌道制御問題に学習則を適用した考察は 幾つか報告されている1,2.

他方，軌道計画問題については，関節座標系で空間経 路が与えられる場合に経路の移動量を用いた簡単なアル ゴリズムで最短時間軌道を求めた Shin らの報告 ${ }^{3}$, 一般 の評価関数の場合に動的計画法を用いた Vukobratovic

* 原稿受付 1988. 3. 1

** 岡山理科大学 工学部 Okayama University of Science ; 1-1, Ridai-cho, Okayama 700, JAPAN

*** 大阪府立大学 工学部 College of Engineering, University of Osaka Prefecture ; 4-804, Mozu-Umemachi, Sakai 591, JAPAN

Key Words : robotic manipulator, optimal trajectory planning, learning method, learning algorithm, learning effect.
らの報告 ${ }^{4}$, 一般の評価関数で, 実行可能解を逐次改善 する方法と動的計画法とを用いる尾崎らの報告 ${ }^{5}$ などが あるが，軌道計画問題に学習的方法を適用した報告は見 当たらないようである.

本報告では，マニピュレータの作業空間でのピックアッ プ動作を想定し, エンドェフェクタの始点; 終点の座標 が与えられた場合の最適軌道計画問題を取り上げる．例 えば, ベルトコンベア上のワークをマニピュレータハン ドでピックアップする作業などでは始点がある程度変動 するし，小さなワークを箱に詰める場合などは終点ああ る程度変動しなければならない.てのようなマニピュレ 一夕の始点, 終点が比較的小さな範囲で繰り返し動作を 行なう場合の最適軌道を学習的に探索する問題を考察す る.

本研究の目的は, 始点, 終点の変動領域内の既知の最 適軌道の情報を用いて新しく与えられる始点, 終点に対 応する最適軌道の探索回数を減少させる一つのアルゴリ ズムを提案し，その有効性をシミュレーションにより確 かめることである. 学習の一つの定義「経験の積み重ね 
により，ある仕事を以前より効率よく出来るようになる こと，または以前出来なかったてとを出来るようになる

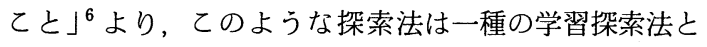
いえる.

本論文の構成は以下のとおりである．2. では多関節 形マニピュレータの最適軌道計画問題を述べ，3. では この軌道計画問題を解くための最大傾斜法による解探索 過程に,「繰り返し試行」と「知識獲得」の考え方より 導かれる探索回数を減少させるための学習的アルゴリズ ムを提案する. 4. では提案したアルゴリズムを最適軌 道の解探索に適用して，アルゴリズムの有効性を 2 関節 形マニピュレータのシミュレーション結果により確かめ る. 最後の 5. では提案したアルゴリズムの有効性のま とめと他の問題への発展性について述べる.

\section{2. 多関節マニピュレータの最適軌道計画 問題}

$n$ 個の回転形関節をむつ直鎖状リンクからなる Fig. 1 のようなマニピュレータの先端位置（エンドェフェクタ $M_{n+1}$ の座標) の始点 $X(0)$, 終点 $X(T)$ が与えられて マニピュレータを運動させる場合の最適軌道計画問題を 考える. ここで時間変数は $t \in[0, T]$ とする.

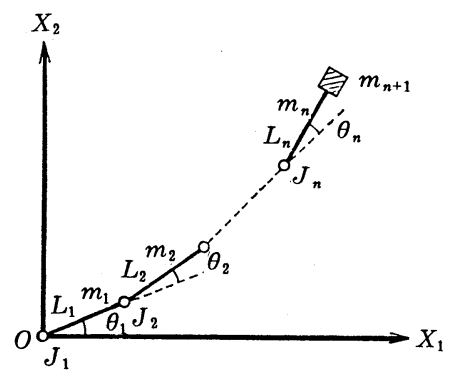

Fig. $1 n$-link manipulator

マニピュレータの運動方程式は次のように表わせる.

$M(\theta) \ddot{\theta}+f(\dot{\theta}, \theta)=\tau$

ここで, $\theta \in R^{n}$ は関節座標ベクトル, $\tau \in R^{n}$ は一般化 カベクトル, $M(\theta) \in R^{n \times n}$ は慣性行列, $f(\dot{\theta}, \theta) \in R^{n}$ は 非線形力ベクトルである.

軌道の境界条件は次のように与える.

$$
\begin{aligned}
& \theta(0)=\theta_{0}, \theta(T)=\theta_{T} \\
& \dot{\theta}(0)=\dot{\theta}(T)=0 \\
& \ddot{\theta}(0)=\ddot{\theta}(T)=0
\end{aligned}
$$

ここで, $\theta_{0}$ は初期関節座標, $\theta_{T}$ は終端関節座標である. 運動開始時, 終了時でマニピュレータは完全に停止する あのとする.

評価関数は次のような積分形のものを考える.

$$
z=\int_{0}^{T} h(\ddot{\theta}, \dot{\theta}, \theta) d t
$$

ここで, $h(\ddot{\theta}, \dot{\theta}, \theta)$ は凸で非負の関数である.

最適軌道計画は，一般に（1）式，(2) 式を制約条件と して（3）式を最小にする $\theta$ を求める問題であるが，本 報告では次のように取り扱う。（2）式を考慮して $i$ 番目 のリンクの $\dot{\theta}$ を次のようにフーリエ級数展開できるも のとする.

$$
\dot{\theta}_{i}=\sum_{j=1}^{m}\left\{a_{i j}\left(\cos \frac{2 \pi j}{T} t-1\right)+b_{i j} \sin \frac{2 \pi j}{T} t\right\}
$$

こてで $i$ はリンク番号 $(1,2, \cdots, n), j$ はフーリエ級数項 番号 $(1,2, \cdots, m), a_{i j}, b_{i j}$ はフーリエ係数である. この ときフーリエ係数は (2) 式より次式を満足しなければな らない.

$$
\begin{aligned}
& \sum_{j=1}^{m} a_{i j} \times T=\theta_{i o}-\theta_{i f} \\
& \sum_{j=1}^{m}\left(j \times b_{i j}\right)=0
\end{aligned}
$$

ここで, $\theta_{i o}, \theta_{i f}$ は $i$ 番目リンクの初期, 終端関節座標 である.

与えられる始点, 終点をひとまとめにして $\left(X^{\prime}(0)\right.$, $\left.X^{\prime}(T)\right)^{\prime} \in R^{6}$ と表わして以後座標べクトルと呼ぶ.た だし（）'は転置を表わす．結局，本報告での最適軌 道計画は，与えられる座標ベクトルに対して，(1) 式, （5）式を満足して（3）式を最小にするパラメータベクト ル $\left(a_{i j}^{\prime}, b_{i j}^{\prime}, T\right)^{\prime} \in R^{2 n m+1}$ を求める問題となる. 以後, $\left(a_{i j}^{\prime}, b_{i j}^{\prime}, T\right)^{\prime}$ を軌道ベクトルと呼ぶ.

（3）式を最小にするパラメータベクトルの存在と一意 性の仮定のもとに, この問題に最大傾斜法を用いて解を 求めることを考える. Fig.1のようなマニピュレータの 作業座標加関節座標への位置の変換問題を一意的に解 く一般的方法はないが, 関節の個数 $n$ が作業座標の次 元数より大ならば解は無数にあるので, $\tau, \dot{\theta}$ の絶対値 に制限のあるときであ $T$ を大きい值にとれば実行可能 解を見つけるのはそれほど困難ではない，実行可能解の うちの適当な軌道ベクトル $\left(a_{i j}^{\prime}, b_{i j}^{\prime}, T\right)^{\prime}$ から出発して 繰り返し計算で (3) 式を小さくするように軌道ベクトル を修正していくと, 最適軌道ベクトル $\left(a_{i j}^{\prime}, b_{i j}^{\prime}, T\right)^{\prime}$ に 収束することをシミュレーションにより示した7. ただ し，一つの最適軌道を決める繰り返し探索回数が 200〜 300 回（2 リンクの場合）から500〜 700 回（３リンクの 場合）を要する. この探索回数はかなりの計算時間を要 するので，探索回数をできるだけ減らしたい.

\section{3. 学習的最適解探索アルゴリズム}

作業空間に基準となる一組の（始点, 終点）の座標べ 
クトル $\left(X^{\prime}(0), X^{\prime}(T)\right)^{\prime}$ (以後, 基準座標ベクトルと呼 ぶ）とそれに対応する最適軌道ベクトル $\left(a_{i j}^{* \prime}, b_{i j}^{* \prime} T^{*}\right)^{\prime}$ (以後, 基準最適軌道べクトルと呼ぶ）は分かっている あのとする. 基準座標ベクトル近傍の与えられる一組の (始点, 終点) に対する最適軌道探索では, 探索開始時 の軌道ベクトルとして基準最適軌道ベクトルを採用する ことは自然である.

こてで, 学習的解探索アルゴリズムにより解が求まる ための条件として，次のような仮定をおく．

\section{[仮定]}

(A 1) 一組の（始点, 終点) 座標ベグトルに対応する最 適軌道ベクトルはただ一つ存在する.

(A 2) 一組の（始点, 終点) 座標ベクトルから最適軌道 ベクトルへの写像は連続である.

これらの仮定が成立するならば，基準座標べクトル近 傍に与えられた（始点, 終点) に対する最適軌道ベクト ルは基準最適軌道ベクトルの近傍にある.

基準座標ベクトルからの微小变化量を $\left(\Delta X^{\prime}(0)\right.$, $\left.\Delta X^{\prime}(T)\right)^{\prime}$, 乙れに対応する基準最適軌道ベクトル $\left(a_{i j}^{* \prime}\right.$, $\left.b_{i j}^{* \prime}, T^{*}\right)^{\prime}$ からの微小変化量を $\left(\Delta a_{i j}^{\prime}, \Delta b_{i j}^{\prime}, \Delta T\right)^{\prime}$ とし て予測軌道べクトル $\left(\bar{a}^{\prime}{ }_{i j}, \bar{b}_{i j}{ }_{i j}, \bar{T}\right)^{\prime}$ を次の線形近似式で 表わす.

$$
\left(\bar{a}_{i j}^{\prime}, \bar{b}_{i j}^{\prime}, \bar{T}\right)^{\prime}=\left(a_{i j}^{* \prime}, b_{i j}^{* \prime}, T^{*}\right)^{\prime}+\left(\Delta a_{i j}^{\prime}, \Delta b_{i j}^{\prime}, \Delta T\right)^{\prime}
$$

各微小変化量の関係む次の線形近似式で表わされるもの とする.

$$
\begin{aligned}
\Delta a_{i j} & =D_{a} \Delta X(0)+E_{a} \Delta X(T) \\
\Delta b_{i j} & =D_{b} \Delta X(0)+E_{b} \Delta X(T) \\
\Delta T & =D_{T} \Delta X(0)+E_{T} \Delta X(T)
\end{aligned}
$$

乙こで, $D_{a}, D_{b}, E_{a}, E_{b} \in R^{n m \times 3}$ は定係数行列であり, $D_{T}, E_{T} \in R^{3}$ は定係数べクトルである. これらの定係数 行列, 定係数べクトルを未知数とする方程式 (7) を解く には基準座標ベクトル近傍の少なくとも 6 個の最適ベク トルが既知であるてとが必要である.

基準座標ベクトルの近傍にある座標ベクトルに対応す る最適軌道ベクトルを求めるのに次のような解探索アル ゴリズムを用いるととを提案する.

\section{[アルゴリズム ]}

(I) 与えられた座標ベクトルが既知の最適軌道ベクト ルに対応する座標ベクトルに等しければ，その最適軌道 ベクトルを解として（I）に戻る，そうでなければ（II） に進む.

（II）与えられた座標ベクトルに対する予測軌道ベクト ルを（6）式より求め，それを探索開始時の軌道ベクトル として最適軌道ベクトルを探索して解とし, 記憶データ
として (III) 亿進む.

（III）求まった最適軌道ベクトルに関する情報を記憶デ 一夕に追加して最小二乗法により新しい係数行列, 係数 ベクトルを (7) 式より求めて ( I ) 亿戻る.

記憶データは与えた座標ベクトル $\left(X^{\prime}(0), X^{\prime}(T)\right)^{\prime}$ と最適軌道ベクトル $\left(a_{i j}^{* \prime}, b_{i j}^{* \prime}, T^{*}\right)^{\prime}$ と繰り返し計算回 数 $k$ とする．乙のアルゴリズムは，座標ベクトルを一 つ与えるごとにループを一巡するので，探索プログラム が実行されると記憶データがだんだん蓄積され, 最終的 には記憶容量の制限で探索プログラムは停止する.

本アルゴリズムでは，探索回数の減少（学習効果）に 次の二種類が期待できる. 探索開始時の軌道ベクトルと して基準最適軌道の代わりに予測軌道を用いる. 予測軌 道は求めるべき最適軌道の線形近似なので, 基準最適軌 道から探索するより屯探索回数の減少（予測による学習 効果）が期待できる. つぎに解探索が進行するにつれて すでに得られた最適予測軌道ベクトルのデータを用いる ので予測軌道の精度向上が見込まれ，乙の精度向上に基 づく探索回数の減少（習熟による学習効果）が期待でき る. どの程度探索回数が減少できるかは, 基準軌道近傍 の非線形性の強さに依存するので，一般的に知る方法は ない。

\section{2 関節マニピュレータの数值シミュレー ション}

前述の探索アルゴリズムの有効性を確かめるために回 転形の 2 関節マニピュレータを平面内で運動させる場合 を取り上げる. リンク数 $n=2$ とフーリエ項数 $m=5$ (この程度の項数であ充分な精度と滑らかさをあつ解が 得られる $\left.{ }^{7}\right)$ を採用する. リンクは断面一様な剛体棒と し，エンドェフェクタは質点とする．また，評価関数の 被積分関数には次式を用いる.

$$
h(\ddot{\theta}, \dot{\theta}, \theta)=c_{1} \tau^{\prime} \tau+c_{2}
$$

ただし， $c_{1}, c_{2}$ は正定数である.乙のとき，(1) 式の慣 性項, 非線形力項の成分は各リンクの長さと質量ならび にエンドェフェクタの質量をパラメータとして次のよう に表わされる.

$$
\begin{aligned}
M_{11}(\theta)= & \left(\frac{1}{3} m_{1}+m_{2}+m_{3}\right) L_{1}^{2}+\left(\frac{1}{3} m_{2}+m_{3}\right) L_{2}^{2} \\
& +\left(m_{2}+2 m_{3}\right) L_{1} L_{2} \cos \left(\theta_{2}\right) \\
M_{12}(\theta)= & M_{21}(\theta)=\left(\frac{1}{3} m_{2}+m_{3}\right) L_{2}^{2} \\
& +\left(\frac{1}{2} m_{2}+m_{3}\right) L_{1} L_{2} \cos \left(\theta_{2}\right) \\
M_{22}(\theta)= & \left(\frac{1}{3} m_{2}+m_{3}\right) L_{2}^{2}
\end{aligned}
$$




$$
\begin{aligned}
f_{1}(\dot{\theta}, \theta)= & -\left(m_{2}+2 m_{3}\right)\left(\dot{\theta}_{1} \dot{\theta}_{2}+\frac{1}{2} \dot{\theta}_{2}^{2}\right) L_{1} L_{2} \sin \left(\theta_{2}\right) \\
& +g\left(\frac{1}{2} m_{1}+m_{2}+m_{3}\right) L_{1} \cos \left(\theta_{1}\right) \\
& +g\left(\frac{1}{2} m_{2}+m_{3}\right) L_{2} \cos \left(\theta_{1}+\theta_{2}\right) \\
f_{2}(\dot{\theta}, \theta)= & \left(\frac{1}{2} m_{2}+m_{3}\right) \dot{\theta}_{1}^{2} \cdot L_{1} L_{2} \sin \left(\theta_{2}\right) \\
& +g\left(\frac{1}{2} m_{2}+m_{3}\right) L_{2} \cos \left(\theta_{1}+\theta_{2}\right)
\end{aligned}
$$

ただし， $\mathrm{g}$ は重力加速度である.なお摩擦力は無視でき るあのとした.

軌道ベクトルは関節座標を定めるが, 関節座標から作 業空間座標への变換は次式で表わされる.

$$
\begin{aligned}
& X_{1}=L_{1} \cos \left(\theta_{1}\right)+L_{2} \cos \left(\theta_{1}+\theta_{2}\right) \\
& X_{2}=L_{1} \sin \left(\theta_{1}\right)+L_{2} \sin \left(\theta_{1}+\theta_{2}\right)
\end{aligned}
$$

与えられた $X(0), X(T)$ から初期時刻での $\theta_{i o}, \theta_{i f}$ へ の変換は (10) 式から一意には決まらないが, 本例では マニピュレータの初期状態は停止しているとしているの で, マニピュレータに働く重力が最小になるように $\theta_{i o}$, $\theta_{\text {if }}$ を決める.

Fig. 2 亿作業空間座標 $\left(X_{1}, X_{2}\right)$ と一つの基準座標へ クトル $(0.5,0.0,0.3,0.31)^{\prime}$ と始点, 終点の近傍を表わ すための局所座標 $\left(\lambda_{1}, \lambda_{2}\right)$ を示す. (9) 式のリンク, エン ドェフェクタの諸元は Table 1 のとおりである. $c_{1}=1$, $c_{2}=10^{5}$ とする. $c_{1}$ に比べて $c_{2}$ に大きな比重をかけて

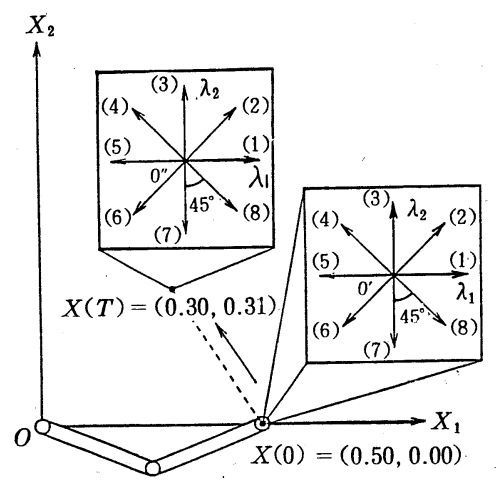

Fig. 2 Base coordinates and local coordinates

Table 1 Dimension and mass of links

\begin{tabular}{|c|c|}
\hline$L_{1}$ & $0.25(\mathrm{~m})$ \\
\hline$m_{1}$ & $23.30(\mathrm{~kg})$ \\
\hline$L_{2}$ & $0.36(\mathrm{~m})$ \\
\hline$m_{2}$ & $4.72(\mathrm{~kg})$ \\
\hline$m_{3}$ & $2.00(\mathrm{~kg})$ \\
\hline
\end{tabular}

いるのでほぼ最短時間制御を目指していることになるが, 得られる軌道は人間の腕の軌道に近い自然なすのと思わ れる (Fig. 3 の軌道略図参照). 最適軌道ベクトルに収 束したかどうかの判定は, 軌道べクトルの各成分の繰り 返し計算一回当たりの相対変動量の絶対值

$$
\left|\frac{a_{i j}^{k}-a_{i j}^{k-1}}{a_{i j}^{k}}\right|\left|\frac{b_{i j}^{k}-b_{i j}^{k-1}}{b_{i j}^{k}}\right|\left|\frac{T^{k}-T^{k-1}}{T^{k}}\right|
$$

の平均值が $10^{-4}$ 以下になれば，収束したものとする. ここで $k$ は繰り返し計算回数である.

基準座標ベクトルに対応する基準最適軌道ベクトルと その略図を Table 2 と Fig. 3 亿示す. 人間が重いもの を持ち上げるときの腕の軌道に近い自然な軌道であるこ とが読み取れる。

予測による学習効果の例を Fig. 4 に示す. 乙れは $X(T)$ を固定して $X(0)$ を局所座標の (1) 方向に動か したときの無次元距離（局所座標の移動距離を基準点間 距離で割ったもの) $d$ と最適軌道べクトルを求めたとき の探索回数 $k$ の関係である. 点線は軌道ベクトルの初 期值に基準最適軌道ベクトルを用いた場合であり, 実線 は（6）式の予測軌道ベクトルを用いた場合である. どの $d$ についてむ約 200 回探索回数が節約でき, 提案したア

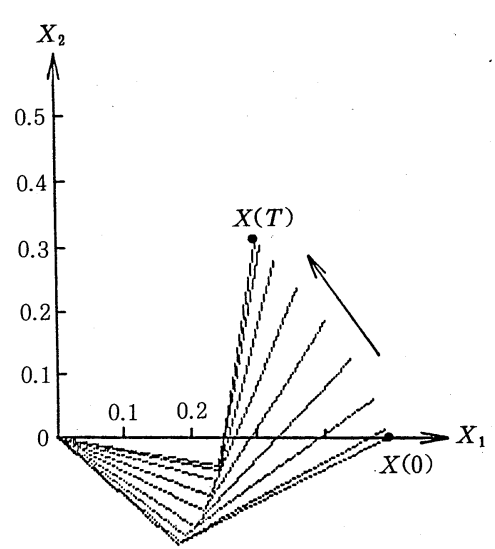

Fig. 3 An optimal reference trajectory

Table 2 Fourier coefficients and motion interval of an optimal reference trajectory

\begin{tabular}{|c|crrrl|}
\hline$j$ & \multicolumn{1}{|c|}{$a_{1}^{*}$} & \multicolumn{1}{c|}{$b_{1}^{*}$} & \multicolumn{1}{c|}{$a_{2}^{*}$} & \multicolumn{1}{c|}{$b_{2}^{*}$} & \\
\hline 1 & -0.3953 & -0.1195 & -0.2359 & 0.3424 & {$[\mathrm{rad} / \mathrm{s}]$} \\
2 & -0.0905 & 0.0066 & -0.0690 & -0.0192 & \\
3 & -0.0409 & 0.0105 & -0.0301 & -0.0310 & \\
4 & -0.0234 & 0.0092 & -0.0161 & -0.0269 & \\
5 & -0.0154 & 0.0076 & -0.0097 & -0.0207 & \\
\hline \multicolumn{5}{|c}{$T^{*}=0.1701[\mathrm{~s}]$} \\
\hline
\end{tabular}




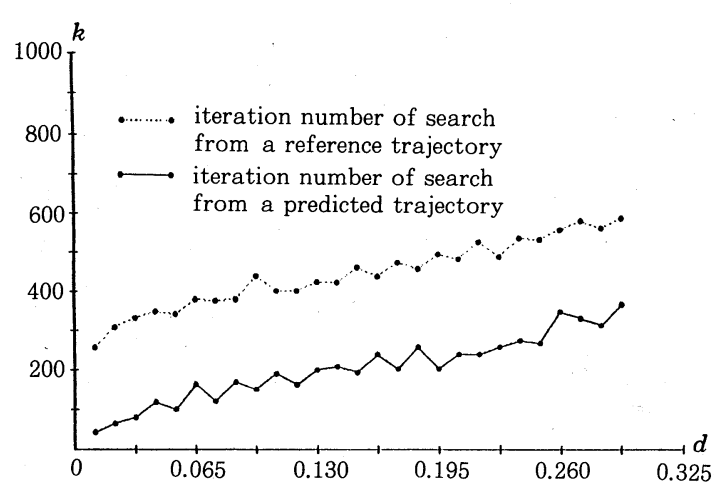

Fig. 4 Iteration number of search in the case of $X(0)$ : changed and $X(T)$ : fixed

ルゴリズムを用いれば探索回数が約 6 分の 1 から 2 分の 1 亿減少する. 局所座標の各方向ごとの探索回数の減少 量を Fig. 5 に示す. $d=0.1$ の場合であり，探索回数は 局所座標で方向性があることが分かる.

$X(0), X(T)$ の両方を同時に局所座標の（4) 方向 に動かしたときの $d$ と $k$ の関係を Fig. 6 に示す. 横軸 の $d$ は $X(0), X(T)$ 各変動の和である. $d=1$ 程度ま では学習効果が認められる.

習熟による学習効果の例として, $\left(X^{\prime}(0), X^{\prime}(T)\right)^{\prime}=$ $(0.4972,0.0028,0.2972,0.3128)^{\prime}$ に対応する最適軌道を 求めたときの探索回数 $k$ を Fig. 7 亿示す. アルゴリズ ムのループでとに一様乱数を用いて $\Delta X(0), \Delta X(T)$ を 発生し，（7）式の係数べクトル，係数行列を求め，それ らを用いた予測軌道からの探索回数 $k$ をループ回数 $N$ に対してプロットしたあのである. $N$ が 200 程度まで は僅かながら $k$ のトレンドの減少が認められる. てれ は習熟による学習効果といえる.

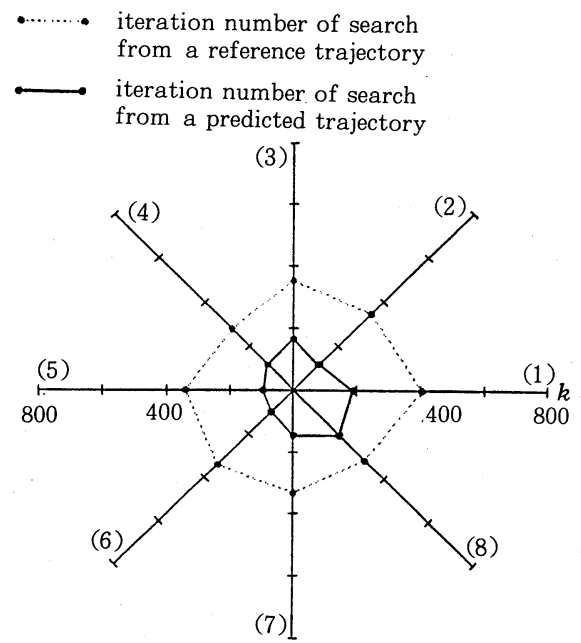

Fig. 5 Iteration number of search in the neighborhood of a reference point

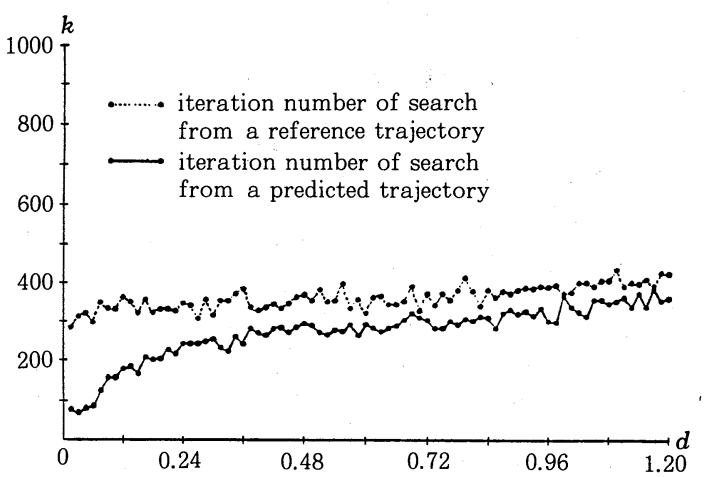

Fig. 6 Iteration number of search in the case of $X(0)$ : changed and $X(T)$ : changed

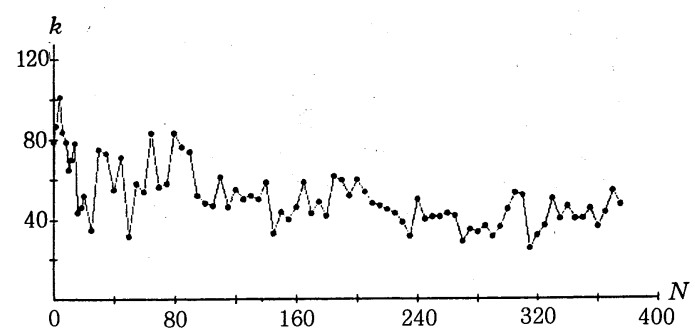

Fig. 7 Iteration number of search in a training process

\section{5. あとがき}

マニピュレータの始点, 終点が指定される最適軌道計 画問題において，一つの学習的解探索アルゴリズムを提 案し, そのアルゴリズムの有効性を 2 リンクマニピュレ ータのシミュレーション結果より検討した. その結果は 以下のようにまとめられる.

（1）探索回数の減少 (学習効果) には二種類ある. 一つ は予測軌道を用いることによる探索回数の減少（予測効 果) であり，屯う一つは予測軌道の改良による探索回数 の減少 (習熟効果) である.

(2) 予測効果による学習効果は基準最適軌道ベクトル に近い探索程大きい. 非常に近い場合は基準值の 6 分の 1 程度の探索回数となるし，また基準座標ベクトルから どの方向にマニピュレータを動かすかによって探索回数 の減少に差がある.

（3）習熱効果については，アルゴリズムのループ回数 が 200 程度までは僅かながら認められる.

探索領域近傍の解の情報を用いて予測解を作るという 本論文で提案したアルゴリズムは，種々の探索問題に応 用が可能と思われる. 例えば, ペイロードの変動する場 合のマニピュレータの最適軌道探索には本報告と全く同 じ手法が適用できる.

最後に本研究の遂行にあたりシミュレーションに従事 
した岡山理科大学大学院学生の鎌田優君に感謝する.

\section{参 考 文 献}

1) 川村, 宮崎, 有本 : ロボットマニピュレータの運動学習制 御; 計測自動制御学会論文集, 22 巻, 4 号, pp. $69 \sim 76$ (1986)

2) 菅沼, 伊藤 : 制御における熟練の獲得と知識表現一多リン ク系への応用一; 計測自動制御学会論文集, 22 巻, 1 号, pp. 84 91 (1986)

3) K. G. Shin \& N. D. Mckay : A Dynamic Programming Approach to Trajectory Planning of Robotic Manipulators ; IEEE Trans. Automat. Contr., Vol. AC-31, No. 6, pp. 491 500 (1986)

4) M. Vukobratovic \& M. Kircanski : A Method for Optimal Synthesis of Manipulation Robot Trajectories ; ASME Journal of Dynamic Systems, Measurement and Control, Vol. 104, pp. 188 193 (1982)

5) 尾崎, 山本, 毛利: 空間経路が指定されるマニピュレータ 動作の軌道計画; 計測自動制御学会論文集, 23 巻, 3 号, pp. 82 87 (1987)

6) O. Barteinstein：ロボティクスにおける学習システム; 日 本ロボット学会誌, 5 巻, 6 号, pp. 495〜500 (1987)

7) 逢坂, 小野, 倉橋 : ロボットマニピュレータの一最適制御 ; 第 4 回日本ロボット学会学術講演会予稿集, pp. $49 \sim 50$ (1986) 